\title{
Anterior Segment Ischemia
}

National Cancer Institute

\section{Source}

National Cancer Institute. Anterior Segment Ischemia. NCI Thesaurus. Code C118861.

Compromise of blood supply to the anterior segment of the eye. 